\title{
Autograft Monocytes: The Bad Humors of Autologous Peripheral Blood Hematopoietic Stem Cell Transplantation
}

\author{
Kerryn Ansell and Luis F Porrata* \\ Division of Hematology, Department of Internal Medicine, Mayo Clinic College of Medicine, Mayo Clinic, Rochester, USA
}

\begin{abstract}
Day 15 absolute lymphocyte count (ALC-15) post-autologous peripheral blood hematopoietic stem cell transplantation (APHSCT) is a prognostic factor for survival. ALC-15 recovery post-APHSCT directly depends on the collected and infused autograft absolute lymphocyte count (A-ALC). However, post-APHSCT relapses are still observed despite higher ALC-15 recovery. Recent studies have shown monocyte-derived cells affect tumor progression by suppression of host anti-tumor immunity. Monocytes are also collected and infused in patients undergoing APHSCT. Therefore this article reviews the possible immunosuppressive mechanisms of the autograft absolute monocyte count (A-AMC) affecting the host immunity and survival in patients undergoing APHSCT.
\end{abstract}

\section{Introduction}

Hematologic Stem Cell Transplant (HSCT) has become a vital option in the treatment armamentarium for hematologic malignancies. The initial hypothesis to support the survival benefit of HSCT relied solely on the rationale behind the use of high dose chemotherapy (HDT) to eradicate tumor cells [1]. To overcome the myelosuppressive effects of the HDT, patients are infused with stem cells to repopulate the bone marrow leading to hematologic engraftment observed by the recovery of white blood cells, red cells and platelets post-AHSCT [1]. Recent understanding of the importance of immune recovery post-HSCT has shifted the paradigm of how HSCT improves clinical outcomes. Inallogeneic stem cell transplantation, it is the current dogma that in the infused donor, allo-reactive lymphocytes produce graft-versus-tumor directly improving the survival of high-risk and/or relapse after standard treatment patients with hematologic malignancies [2]. The faster recovery of the absolute lymphocyte count at day 15 (ALC-15) after autologous peripheral hematopoietic stem cell transplantation (APHSCT) has been reported and confirmed to be a prognostic factor for superior clinical outcomes [3-11]. The ALC-15 recovery post-APHSCT directly depends on the amount of infused autograft absolute lymphocyte count (A-ALC) collected during stem cell apheresis, supporting the concept of autologous graftversus-tumor effect without the detrimental effects of graft-versustumor effect observed in allogeneic stem cell transplantation [12-14]. However, relapses in post-APHSCT in patients with higher ALC-15 recovery are still observed. Recent studies suggest that the collected and infused autograftmonocytes influence immune recovery and survival by inhibiting the anti-tumor hostimmunity post-APHSCT [15].

Myeloid-derived suppressor cells (MDSCs) are a heterogeneous population of cells of myeloid progenitor and immature myeloid cells involved in tumor-associated immune suppression [16]. Two main subsets of MDSCs have been proposed in humans: the granulocytic and the monocytic MDSCs [17]. The human monocytic MDSCs subsets has been characterized as monocytic $\mathrm{CD}_{1} 4^{+}$cells with low levels of lack of the antigen presenting HLA-DR molecules (CD14+HLA-DRlow/neg. cells) [17].Our group reported the presence of circulating immunosuppressive CD14 HLA-DR ${ }^{+}$lowneg peripheral blood monocytic MDSCs in patients with lymphoma [18]. These circulating CD14 ${ }^{+} H L A-D R^{\text {low/neg }}$ monocytes are recruited and transformed into tumor-associated macrophages by the tumor impacting survival in cancer patients [19-22]. Based on these findings, we evaluated if monocytes have any impact on survival in lymphoma patients treated with APHSCT. We reported that during stem cell apheresis, in addition to collecting lymphocytes, monocytes were also collected [15]. The autograft absolute monocyte count (A-AMC), when infused, was the main predictor of monocyte recovery postAPHSCT [15]. A higher day 15 absolute monocyte count (AMC-15) was associated with an inferior survival post-APHSCT [15]. We then combined the ALC-15 (i.e., a surrogate marker of host immunity) and AMC-15 (i.e., a surrogate marker of tumor microenvironment) as a ratio [15]. We reported that patients with an ALC/AMC-15 ratio $\geq$ 1 experienced superior survival compared to those who did not [15]. Thus, the importance of the balance between host immunity (i.e., ALC-15) and tumor microenvironment (i.e., AMC-15) for the clinical outcomes of patients treated with APHSCT was brought into question. Furthermore, AMC-15 recovery directly depends on the amount of infused A-AMC, which may lead to abrogation of the immunologic anti-tumor effect of a higher ALC-15 recovery post-APHSCT [15]. For example, monocyte-induced immune tolerance appears to be caused by a period of "transient immunodeficiency" [23], accompanied by a simultaneous "state of enhanced activation" by post-APHSCT monocytes. This state is characterized by the secretion of unusually large quantities of kynurenine by monocytes post-APHSCT, triggered by even the slightest stimuli. Thus, this magnified stimulationinduced kynurenine secretion by post-APHSCT monocytes may be one of the possible mechanisms of the monocytes' documented suppressor activity, causing T-cell inhibition through apoptosis [23]. Furthermore, we recently reported in Hodgkin lymphoma patients in complete remission at day 100 post-APHSCT superior survival with a higher ALC/AMC ratio at day 100 (ALC/AMC-100) compared with those with a low ALC/AMC-100 by landmark analysis from day 100

*Corresponding author: Luis F Porrata, MD, Assistant Professor, Mayo Clinic, 200 First Street SW, Rochester, Minnesota, 55905, USA, Tel: 507-284-3158; Fax: 507-266-4972; E-mail: porrata.luis@mayo.edu

Received August 23, 2013; Accepted October 10, 2013; Published October 12 2013

Citation: Ansell K, Porrata LF (2013) Autograft Monocytes: The Bad Humors of Autologous Peripheral Blood Hematopoietic Stem Cell Transplantation. J Stem Cell Res Ther S3: 005. doi:10.4172/2157-7633.S3-005

Copyright: ( 2013 Ansell K, et al. This is an open-access article distributed under the terms of the Creative Commons Attribution License, which permits unrestricted use, distribution, and reproduction in any medium, provided the original author and source are credited. 
arguing in favor on the concept of post-APHSCT immunosurveillance by balancing the interaction between host immunity (i.e., ALC) and tumor microenvironment (i.e., AMC) [24]. In addition, the ALC/ AMC ratio obtained from the standard complete blood cell count provides a simple standardized test to assess the interaction between host immunity and tumor microenvironment in comparison to geneexpression profiling with the practical limitation of requiring fresh frozen tissue samples to analyze and in patients in complete remission like the patients included in our study [24] no tumor samples are available to biopsy to provide a dynamic real-time interaction between host response and tumor. Therefore, this article reviews the possible mechanisms of the immunosuppressive effects of A-AMC affecting the autograft versus tumor effect in patients undergoing APHSCT.

\section{MDSCs mechanisms of immune effector cells suppression}

T-cell lymphocytes inhibition by immunosuppressive cytokines: MDSCs at the tumor site can differentiate into tumorassociated macrophages (TAMs). TAMs acquire the ability to produce immunosuppressive cytokines such as interleukin-1 $\beta$ (IL-1 $\beta$ ), IL-6, IL10 , transforming growth factor- $\beta$ (TCF $\beta$ ), and tumor-necrosis factoralpha (TNF- $\alpha$ ) [17]. In the allogeneic stem cell transplantation setting IL-6 and IL-10 has been positively correlated with the CD14 ${ }^{+}$HLADR ${ }^{\text {low/neg }}$ cells [25]. Specifically in APHSCT, two immunosuppressive cytokine produced by MDSCs/TAM had been identified from the autograft absolute monocyte count (A-AMC) collected during stem cell collection: IL-10 and TNF- $\alpha$. Singh et al. [26], reported high levels of IL-10 mRNA produced by the A-AMC in the autograft stem cell collection product, directly correlating with $\mathrm{T}$-cell inhibition activity as well as decreased phytohemagglutinin (PHA) stimulation of the autograft T-cells collected and infused when compared with normal peripheral blood mononuclear cells. High levels of mRNA TNF- $\alpha$ have been documented in the autograft products for patients undergoing APHSCT produced by the A-AMC [26]. Antibodies directed against TNF- $\alpha$ were able to abolish the autograft T-cells inhibitory activity produced by this monokine from the A-AMC [26].

Alteration of antigen recognition and activation: MDSCs produce elevated levels of reactive oxygen species (ROS) [16-17] including peroxynitrite (ONOO-) and upregulate signal transducer and activator of transcription 3 (STAT3) activity. This is associated with an increase in arginase 1 activity and low levels of nitric oxide (NO) production [16-17]. MDSCs can take up, process and present antigens to antigenspecific $\mathrm{CD}^{+} \mathrm{T}$ cells. During cell to cell interaction, MDSCs disrupt the biding of specific peptide-major histocompatibility complex (pMHC) dimers to $\mathrm{CD} 8^{+} \mathrm{T}$ cells through nitration of tyrosines by the production of peroxynitrite, leading $\mathrm{CD}^{+} \mathrm{T}$ cells unable to response to specific peptide [27]. In allogeneic stem cell transplantation, down regulation of the expression of $\mathrm{CD} 3 \zeta$-chain has been reported by indoleamine 2, 3-dioxygenase (IDO) produced by $\mathrm{CD}_{14}{ }^{+}$HLA-DR ${ }^{\text {low/ngeg. }}$ cells [25]. Blocking IDO restored the $\mathrm{CD} 3 \zeta$-chain expression as well as increased production of interferon- $\Upsilon$, thus T cell activation [25]. No studies are currently available in the APHSCT setting; nevertheless, it is reasonable to hypothesize a similar process of $\mathrm{T}$-cell immunosuppression by the A-AMC could occur.

Induction of regulatory T-cells: In vivo studies have described the ability of MDSCs to promote the induction of forkhead box P3 (FOXP3) regulatory $\mathrm{T}\left(\mathrm{T}_{\mathrm{reg}}\right)$ cells [28-29]. The induction of $\mathrm{T}_{\mathrm{reg}}$ by MDSCs required IL-10, arginase 1 , and the capture, processing and presentation of tumor-associated antigens by MDSCs [30]. In a recent study in multiple myeloma patients mobilized with high-dose cyclophosphamide and granulocyte colony-stimulating factor (G-SCF) for APHSCT identified high levels in the autograft of CD $4^{+} \mathrm{CD} 25^{\text {high }} \mathrm{T}_{\mathrm{re}}$ expressing high levels of FOXP3, CTLA-4, and GITR and displaying in vitro suppressive properties [31]. Further studies are warranted to see if A-AMC/MDSCs have any impact in the induction and sustained production of $\mathrm{T}_{\text {reg }}$ in APHSCT.

MDSCs-T-cell Fas/Fas-Ligand (FasL) interaction: In vivo studies have shown MDSCs to express the death receptor Fas [32]. Activated T-cell expressing FasL induces apoptosis in MDSCs identifying a mechanism of regulating MDSCs levels. This finding suggests a retaliatory relationship between T-cells and MDSCs in relation to MDSC s suppressing T-cells activation; however, once activated T-cells mediate MDSCs apoptosis [32]. In APHSCT, autograft A-AMC FasL expression is found in significantly greater amounts compared to controls. Studies on these increased quantities of FasL have suggested that these activated FasL-expressing monocytes interact with activated Fas+ CD4+ T lymphocytes, causing apoptosis and leading to the destruction of CD4+ T cell populations, about $28-51 \%$ of $\mathrm{CD} 4+$ cells [33-34]. CD8+ cells, unlike CD4+ T cells, do not express elevated quantities of Fas expression and are possibly less targeted by FasL+ monocytes to the same degree as $\mathrm{CD} 4+$ cells; this results in a preferential deletion of post-APHSCT CD4+ T-cells and ultimately a shift in the CD4+/CD8+ ratio [35]. FasL+ monocytes deplete CD4+ cells", thus rendering $\mathrm{CD} 8+$ cells inactive, and contributing to the suppression of the host immunity in APHSCT.

Autograft monocytes and Natural killer (NK) cells: Greater NK cell counts have been correlated with higher ALC-15 recovery and found to be the key lymphocyte subset at day 15 post-APHSCT predicting clinical outcomes [36]. In the presence of A-AMC, NK cells are found to be significantly decreased. A study conducted by Ageitos et al. [37], documented this NK cell decrease in APHSCT autografts, and demonstrated that the presence of A-AMC affects both the function and proliferation ability of NK [37].

\section{Stem Cell Mobilization in APHSCT}

Both Granulocyte Colony-Stimulating Factor (G-CSF) and Granulocyte Macrophage Colony-Stimulating Factor (GM-CSF) have been used to mobilize and collect the desired quantity of CD34+ stem cells to proceed with APHSCT [38-39]. Recent studies have found that the products of the stem cell transplant autografts mobilized by C-CSF or GM-CSF have a much greater quantity of CD- $14^{+}$monocytes than controls [39]. Studies of monocyte-associated suppressive activity revealed a direct relationship between the number of $\mathrm{CD} 14^{+}$cells and suppressor cell function in mobilized cell products [40] and the characterization of the cells as monocyte lineage [40] up to $40 \%$ of the cells in the autograft of mobilized stem cell products by G-CSF/GMCSF are shown to be a CD14 $14^{+}$myeloid cell [41] and up to $10 \%$ of the peripheral blood leukocytes following APHSCT [42] were identified as $\mathrm{CD} 14^{+}$suppressive activity [33]. In addition to G-CSF and GM$\mathrm{CSF}$, Plerixafor is in current use for the mobilization of $\mathrm{CD} 34^{+}$stem cells for APHSCT. Mechanism of action of plerixafor is attributed to be a reversible and transient disruption of the interaction between the chemokine receptor CXCR4 and its ligand chemokine CXCL12 (previously known as stromal derived factor 1 ) which is accompanied by a rapid (8-11 hours) release of $\mathrm{CD} 34^{+}$cells from the bone marrow niche into the circulation [43]. Our group reported that Plerixafor can also mobilized lymphocytes leading higher autograft absolute lymphocyte count (A-ALC) collection affecting clinical outcomes post-APHSCT [44]. Recently, Plerixafor has been shown to mobilize monocyte affecting the numbers of A-AMC [45]. Further studies 


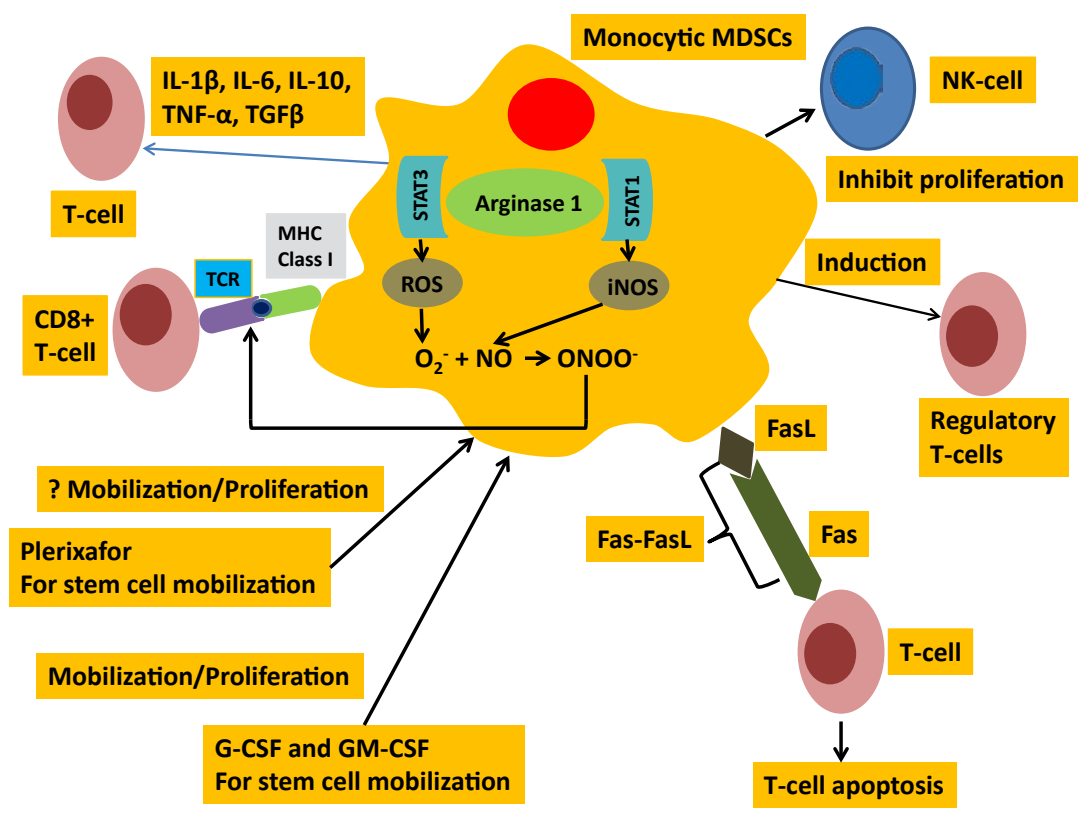

Figure 1: Possible Immunosuppressive mechanisms of Autograft-Absolute Monocyte Count (A-AMC)/Monocytic Myeloid-Derived Suppressor Cells (MDSCs). This schematic diagram depicts possible immunosuppressive mechanisms of A-AMC/MDSCs including the production of immunosuppressive cytokine; disruption of the major histocompatability complex class 1 receptor causing T-cels to become unresponsive to antigen-specific; Fas-FasLinteraction leading to T-cell apoptosis; induction of regulatory T-cells; and inhibition of natural killer (NK) cells function/proliferation. Granulocyte-Colony Stimulating-Factor (G-CSF), GranulocyteMacrophages Colony Stimulating-Factor (GM-CSF) and \pm Plerixafor mobilized higher numbers of monocytes in the peripheral blood of patients leading to higher numbers of aphorized and collected A-AMC.

are needed to identify if Plerixafor mobilized immunosuppressive CD14+HLA-DR ${ }^{\text {low/neg }}$ monocytic MDSCs.

\section{Conclusion}

This article reviewed mechanisms associated with the negative immunosuppressive effects of A-AMC/MDSCs that may impact the clinical outcomes of patients undergoing APHSCT. In the allogeneic stem cell transplantation setting, the adoptive transfer of MDSCs improves the alloreactivity in preclinical graft-versus-host disease [25]. Thus, the use of MDSCs is an attractive idea in allogeneic stem cell transplantation in conjunction with $\mathrm{T}_{\text {rea }}$ and mesenchymal stem cell-based therapies to minimize the side effects of graft-versus-host disease. However, in APHSCT, the immunosuppressive effects of A-AMC/MDSCs possibly mediated through: 1) the production of IL10 and TNF- $\alpha$; 2) the induction of $\mathrm{T}_{\text {reg }}$; 3) Fas/Fas-Ligand activation resultingin T-cells apoptosis; and 4) the down regulation of NK cell activity and proliferation, mostlikely explaining the inferior clinical outcomes of patients achieving a high AMC-15 and low ALC-15 recovery post-APHSCT (see Figure 1).

The identification of the negative prognosis based on the A-AMC provides a new incentive to minimize A-AMC collection with the hope to improve survival post-APHSCT, as the current stem cell mobilization agents (G-CSF, GM-CSF and possibly Plerixafor) has been associated with the mobilization of immunosuppressive monocyte leading to higher collection of A-AMC. These observations give a platform to develop autograft engineering therapies to minimize the collection and infusion of immunosuppressive A-AMC/MDSCs in the APHSCT setting. Carbonyl-iron column suspension has been a commonly preferred method of removing CD-14+ monocytes, and would be ideal for our proposed method of intervention. In column suspension, a magnet is introduced and results in cell suspension; because monocytes contain high percentages of iron, they are attracted to the magnet and can easily be isolated and removed. In studies that used this same method [37], the removal of A-AMC resulted in the expansion and restoration of autograft $\mathrm{T}$ and $\mathrm{NK}$ cells immunologic function and proliferation. Therefore, the removal of CD-14+ A-AMC from autograft products by column-suspension during mobilized apheresis may provide an avenue to improve immune recovery and reduce treatment failure post-APHSCT.

\section{References}

1. Porrata LF, Litzow MR, Markovic SM (2001) Immune reconstitution after autologous hematopoietic stem cell transplantation. Mayo Clinic Proceeding 76: 407-412.

2. Appelbaum FR (2001) Haematopoietic cell transplantation as immunotherapy Nature 411: 385-389.

3. Porrata LF, Gertz MA, Inwards DJ, Litzow MR, lacy MQ, et al. (2001) Early lymphocyte recovery predicts superior survival after autologous hematopoietic stem cell transplantation in multiple myeloma and non-Hodgkin lymphoma. Blood 98: 579-585.

4. Porrata LF, Litzow MR, Tefferi A, Letendre L, Kumar S, et al. (2002) Early lymphocyte recovery is a predictive factor for prolonged survival after autologous hematopoietic stem cell transplantation for acute myelogenous leukemia. Leukemia 16: 1311-1318.

5. Porrata LF, Inwards DJ, Micallef IM, Ansell SM, Geyer SM, et al. (2001) Early lymphocyte recovery post-autologous haematopoietic stem cell transplantation is associated with better survival in Hodgkin's disease. $\mathrm{Br} \mathrm{J}$ Haematol 117 629-633.

6. Porrata LF, Gertz MA, Litzow MR, Lacy MQ, Dispenzieri A, et al. (2005) Early lymphocyte recovery predicts superior survival after autologous hematopoietic stem cell transplantation for patients with primary systemic amyloidosis. Clinical Cancer Research 11: 1210-1218.

7. Joao C, Porrata LF, Inwards DJ, Ansel SM, Micallef IN, et al. (2006) Early lymphocyte recovery after autologous stem cell transplantation predicts superior survival in mantle-cell lymphoma. Bone Marrow Transplant 37: 865871.

8. Boulassel MR, Herr AL, deB Edwards MD, Galal A, Lachance S, et al 
Citation: Ansell K, Porrata LF (2013) Autograft Monocytes: The Bad Humors of Autologous Peripheral Blood Hematopoietic Stem Cell Transplantation. J Stem Cell Res Ther S3: 005. doi:10.4172/2157-7633.S3-005

(2006) Early lymphocyte recovery following autologous peripheral stem cell transplantation is associated with better survival in younger patients with lymphoproliferative disorders. Hematology 11: 165-170.

9. Kim H, Sohn HJ, Kim S, Lee JS, Kim WK, et al. (2006) Early lymphocyte recovery predicts longer survival after autologous peripheral blood stem cell transplantation in multiple myeloma. Bone Marrow Transplant 37: 1037-1042.

10. Kim H, Sohn HJ, Kim SE, Kang HJ, Park S, et al. (2004) Lymphocyte recovery as a positive predictor of prolonged survival after autologous peripheral blood stem cell transplantation in T-cell non-Hodgkin's lymphoma. Bone Marrow Transplant 34: 43-49.

11. Gordan LN, Sugrue MW, Lynch JW, Williams KD, Khan SA, et al. (2003) Correlation of early lymphocyte recovery and progression-free survival after autologous stem-cell transplant in patients with Hodgkin's and non-Hodgkin's Lymphoma. Bone Marrow Transplant 31: 1009-1013.

12. Porrata LF, Litzow MR, Inwards DJ, Gastineau DA, Moore SB, et al. (2004) Infused peripheral blood autograft absolute lymphocyte count correlates with day 15 absolute lymphocyte count and clinical outcome after autologous peripheral blood hematopoietic stem cell transplantation in non-Hodgkin's lymphoma. Bone Marrow Transplant 33: 291-298.

13. Porrata LF, Gertz MA, Geyer SM, Litzow MR, Gastineau DA, et al. (2004) The dose of infused lymphocytes in the autograft directly correlates with clinical outcomes after autologous peripheral blood hematopoietic stem cell transplantation in multiple myeloma. Leukemia 18: 1085-1092.

14. Hiwase DK, Hiwase S, Bailey M, Bollard G, Schwarer AP (2008) Higher infused lymphocyte dose predicts higher lymphocyte recovery, which in turn, predicts superior overall survival following autologous hematopoietic stem cell transplantation for multiple myeloma. Biol Blood Marrow Transplant 14: 116124.

15. Porrata LF, Inwards DJ, Ansell SM, Micallef IN, Johnston PB, et al. (2011) Day 15 peripheral blood lymphocyte/monocyte ratio post-autologous peripheral hematopoietic stem cell transplantation and survival in diffuse large B-cell lymphoma. J Stem Cell Res Ther.

16. Talmadge JE, Gabrilovich DI (2013) History of myeloid-derived suppressor cells. Nat Rev Cancer 13: 739-752.

17. Gabrilovich DI, Nagaraj S (2009) Myeloid-derived suppressor cells as regulators of the immune system. Nat Rev Immunol 9: 162-172.

18. Lin Y, Gustafson MP, Bulur PA, Gastineau DA, Witzig TE, et al. (2011) Immunosuppressive CD14+ HLA-DR (low)/-monocytes in B-cell non-Hodgkin lymphoma. Blood 117: 872-881.

19. Lenz G, Wright G, Dave SS, Xiao W, Powell J, et al. (2008) Stromal gene signatures in large B-cell lymphomas. N Engl J Med 359: 2313-2323.

20. Dave SS, Wright G, Tan B, Rosenwald A, Gascoyne RD, et al. (2004) Prediction of survival in follicular lymphoma based on molecular features of tumor-infiltrating immune cells. N Engl J Med 351: 2159-2169.

21. Wilcox RA, Wada DA, Ziesmer SC, Elsawa SF, Comfere NI, et al. (2009) Monocytes promote tumor cells survival in T-cell lymphoproliferative disorders and are impaired in their ability to differentiate into mature dendritic cells. Blood 114: $2936-2944$

22. Kusmartsev S, Nefedova Y, Yoder D, Gabrilovich D (2004) Antigen-specific inhibitors of $\mathrm{CD} 8+\mathrm{T}$ cell response by immature myeloid cells in cancer is mediated by reactive oxygen species. J Immunol 172: 989-999.

23. Hainz U, Obexer P, Winkler C, Sedlmays $P$, Takikawa O, et al. (2005) Monocyte mediated T-cell suppression and augmented monocyte tryptophan catabolism after human hematopoietic stem cell transplantation. Blood 105: 4127-4134

24. Porrata LF, Inwards DJ, Ansell SM, Micallef IN, Johnston PB, et al. (2013) Day 100 peripheral blood absolute lymphocyte/monocyte ratio and survival in classical Hodgkin's lymphoma post-autologous peripheral blood hematopoietic stem cell transplantation. Bone Marrow Res 2013: 658371.

25. Mougiakakos D, Jitschin R, von Bahr L, Poschke I, Gary R, et al. (2013) Immunosuppressive CD14+ HLA-DR low/neg. IDO+ myeloid cells in patients following allogeneic hematopoietic stem cell transplantation. Leukemia 27: 377-388.

26. Singh RK, Ino K, Varney ML, Heimann DG, Talmadge JE (1999) Immunoregulatory cytokines in bone marrow and peripheral blood stem cell products. Bone Marrow Transplant 23: 53-62.

27. Nagaraj S, Gupta K, Pisarev V, Kinarsky L, Sherman S, et al. (2007) Altered recognition of antigen is a mechanism of CD8+ T cell tolerance in cancer. Nat Med 13: 828-835.

28. Yang R, Cai Z, Zhang Y, Yutzy WH, Roby KF, et al. (2006) Cd 80 in immune suppression by mouse ovarian carcinoma-associated $\mathrm{Gr}-1+\mathrm{CD} 11 \mathrm{~b}+$ myeloid cells. Cancer Res 66: 6807-6815.

29. Huang B, Pan PY, Li Q, Sato AL, Levy DE, et al. (2006) Gr-1 + CD115+ immature myeloid suppressor cells mediate the development of tumor-induced $\mathrm{T}$ regulatory cells and T cell anergy in tumor-bearing host. Cancer Res 66 1123-1131.

30. Derafini P, Mgebroff S, Noonan K, Borrello I (2008) Myeloid-derived suppressor cells promote cross-tolerance in B-cell lymphoma by expanding regulatory $T$ cells. Cancer Res 68: 5439-5449.

31. Condomines M, Quittel P, Lu ZY, Nadal L, Latry $P$, et al. (2006) Functional regulatory $T$ cells are collected in the stem cell autografts by mobilization with high-dose cyclophosphamide and granulocyte colony-stimulating factor. J Immunol 176: 6631-6639.

32. Sinha P, Chornoguz O, Clements VK, Artemenko KA, Zubarev RA, et al. (2011) Myeloid-derived suppressor cells express the death receptor Fas and apoptose in response to T-cell expression FasL. Blood 117: 5381-5390.

33. Singh RK, Varney MC, Buyukberber S, Ino K, Ageitos A, et al. (1999) Fas FasL-mediated CD4+ T-cell apoptosis following stem cell transplantation. Cancer Res 59: 3107-3111.

34. Talmadge JE (2003) Hematopoietic stem cell graft manipulation as a mechanism of immunotherapy. Int Immunopharmacol 3: 1121-1143.

35. Talmadge JE, Singh RK, Ino K, Ageitos A, Buyukberber S (2000) Mechanisms of immune dysfunction in stem cell transplantation. Int J Immunopharmacol 22 1041-1056.

36. Porrata LF, Inwards DJ, Ansell SM, Micallef IN, Johnston PB, et al. (2008) Early lymphocyte recovery predicts superior survival after autologous stem cell transplantation in non-Hodgkin's lymphoma: a prospective study. Biol Blood Marrow Transplant 14: 807-816.

37. Ageitos AG, Ino K, Ozerol I, Tarantolo S, Heimann DG, et al. (1997) Restoration of $\mathrm{T}$ and NK cell function in GM-CSF mobilized stem cell products from breast cancer patients by monocyte depletion. Bone Marrow Transplant 20: 117-123.

38. Cottler-Fox MH, Lapidot T, Petit I, Kollet O, DiPersio JF, et al. (2003) Stem cell mobilization. Hematology Am Soc Hematol Educ Program 1: 419-437.

39. Ino K, Singh RK, Talmadge JE (1997) Monocytes from mobilized stem cells inhibit T-cell function. J Leukoc Biol 61: 583-591.

40. Talmadge JE, Reed EC, Kessinger A, Kuszunski CA, Perry GA, et al. (1996) Immunologic attributes of cytokine mobilized peripheral blood stem cells and recovery following transplantation. Bone Marrow Transplant 17: 101-109.

41. Wanebo HJ, Riley T, Katz D, Pace RC, Johns ME, et al. (1988) Indomethacin sensitive suppressor-cell activity in head and neck cancer patients. The role of the adherent mononuclear cell. Cancer 61: 462-474.

42. Laoui D, Van Overmeire E, Movahedi K, Van den Bossche J, Schouppe E, et al. (2011) Mononuclear phagocyte heterogeneity in cancer: different subsets and activation states reaching out at the tumor site. Immunobiology 216: 11921202.

43. Hendrix CW, Flexner C, MacFarland RT, Giandomenico C, Fuchs EJ, et al. (2000) Pharmacokinetics and safety of AMD3100 a novel antagonist of the CXCR-4 chemokine receptor in human volunteers. Antimicrob Agents Chemother 44: 1667-1672.

44. Holtan SC, Porrata LF, Micallef INM, Padley DJ, Inwards DJ, et al. (2007) AMD3100 affects autograft lymphocyte collection and progression-free survival after autologous stem cell transplantation in non-Hodgkin lymphoma. Clin Lymphoma Myeloma 7: 315-318.

45. Varmavuo V, Mantymoa P, Kuittenen T, Nousiainen T, Jantunene E, et al. (2012) Pre-emptive plerixafor injection increases blood neutrophil, lymphocyte and monocyte in addition to CD34+ counts in patients with non-Hodgkin lymphoma mobilized poorly with chemotherapy plus G-CSF. Potential implications for apheresis and graft composition. Transfus Apher Sci 46: 257-262. 